1 Despommier DD, Gwadz RW, Hotez PJ. Cestodes. In: Parasitic diseases. 3rd edn. New York: Springer-Verlag, 1995; pp 75-106.

2 Beck JW, Davies JE. The cyclophyllidean tapeworms Beck JW, Davies JE. The cyclophyllidean tapeworms (Cyclophyllidea). In: Medical parasitolog

3 Keeling JED. The chemotherapy of cestode infections. Adv Chemother 1978; 3: 109-52.
4 Groll E. Praziquantel for cestode infections in man. Acta Tropica 1980; 37: 293-6.

5 Miyazaki I. Taeniasis. In: An illustrated book of helminthic zoonoses. Tokyo: International Medical Foundation of zoonoses. Tokyo: Internation,
Japan, 1991; pp 224-47.

\title{
Abdominal pain in a cirrhotic patient with ascites
}

\author{
Ivan Touze, Tarik Asselah, Arnaud Boruchowicz, Jean-Claude Paris
}

A 45-year-old woman had been treated by our medical service for alcoholic cirrhosis and ascites. She had a reducible umbilical hernia. Frequent large-volume paracentesis was required to control ascites. Two days after one of the periodic paracenteses, she complained of abdominal pain, vomited and was hospitalised. A plain radiograph of the abdomen was performed (figure).

Clinique des maladies de l'appareil digestif et de la nutrition,

Hopital Huriez,

CHRU Lille, 59037

Lille, France

I Touze

T Asselah

A Boruchowicz

J-C Paris

Accepted 20 March 1997

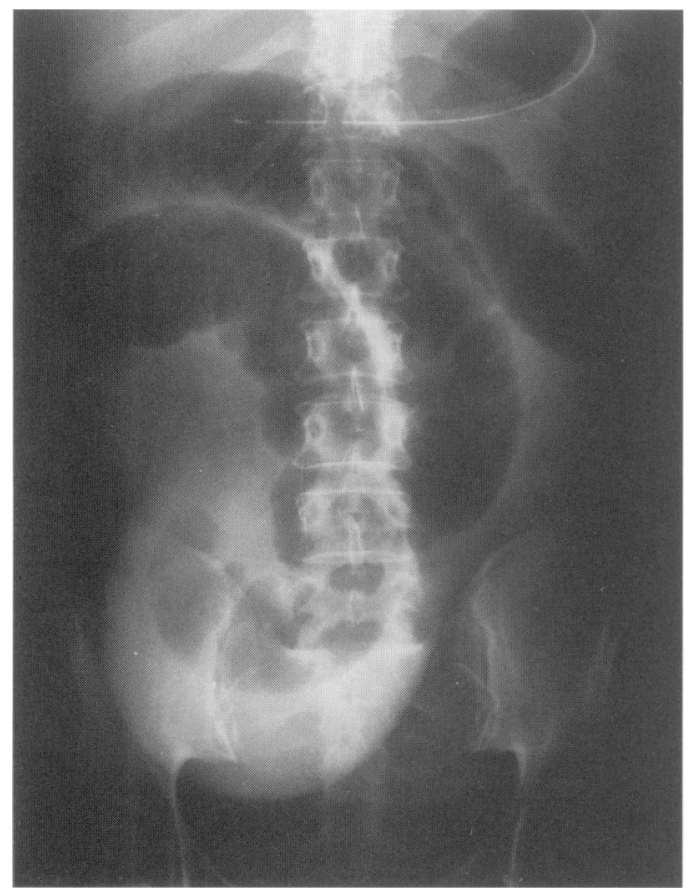

\section{Questions}

1 What does the abdominal X-ray show? 2 What is the most probable diagnosis? 3 How would you treat this patient?

Figure Plain abdominal X-ray 


\section{Answers}

QUESTION 1

The abdominal X-ray shows an abdominal circular opacity with an incarcerated dilated small bowel loop.

\section{QUESTION 2}

Small bowel obstruction caused by incarcerated umbilical hernia following paracentesis in a cirrhotic patient. Physical examination showed high-pitched bowel sounds and a tender, irreducible, umbilical hernia.

\section{QUESTION 3}

Emergency surgical exploration is indicated. This confirmed incarceration of umbilical hernia and ascites sequestration localised within the hernia. An emergency herniorrhaphy was required but small bowel resection was not necessary and the patient survived.

\section{Discussion}

Umbilical hernias are quite common in cirrhotic patients with ascites. Complications of this condition are mainly leakage, ulceration, rup-

1 Chapman CB, Snell AM, Rowntree LG. Decompensated portal cirrhosis. Report on one hundred and twelve cases. Clinical features of the ascitic stage of cirrhosis of the liver. fAMA 1981; 97: 237-44.

2 Baron HC. Umbilical hernia secondary to cirrhosis of the liver. Complications of surgical correction. $N$ Engl $f \mathrm{Med}$ 1960; 263: 824-8.

3 Lemmer JH, Strodel WE, Eckhauser FE. Umbilical hernia incarceration: a complication of medical therapy of ascites. Am 7 Gastroenterol 1983; 78: 295-6. ture, and incarceration. ${ }^{1}$ Incarcerated umbilical hernia complicating removal of the ascites (by paracentesis, shunt, or medical therapy) has already been reported. ${ }^{2-4}$ Sudden decompression probably leads to decreased tension on the hernia ring which subsequently narrows in size and traps the hernia sac contents. ${ }^{2}$ This unusual complication is potentially fatal.

Since there has been a resurgence of interest in large volume paracentesis, ${ }^{5}$ this case is a reminder that this routine procedure still carries risks and that the possibility of incarceration should be kept in mind. We recommended that before beginning therapy for ascites, patients be examined closely for the presence of umbilical hernias and, if present, should be educated about the possibility of incarceration.

\section{Final diagnosis}

Incarcerated umbilical hernia in a cirrhotic patient with ascites.

Keywords: incarcerated umbilical hernia, cirrhosis, paracentesis

$4 \mathrm{Chu} \mathrm{KM}, \mathrm{McCaughan} \mathrm{GW}$. Iatrogenic incarceration of umbilical hernia in cirrhotic patients with ascites. $A m \mathcal{F}$ Gastroenterol 1995; 90: 2058-9.

5 Conn HO. The paracentesis pendulum. Hepatology 1985; 5 : $521-2$. 